\title{
CONTRIBUIÇÕES DA LINGUÍSTICA PARA O ENSINO DA TRADUÇÃO
}

\author{
por \\ Maria Candida Rocha Diaz Bordenave \\ Tese apresentada como requisito parcial para a obtenção do grau de \\ Mestre em Língua Portuguesa - Linguística \\ Professor Orientador: Jürgen Heye \\ Pontifícia Universidade Católica do Rio de Janeiro \\ Departamento de Letras e Artes \\ Rio de Janeiro, julho de 1976
}




\section{RESUMO}

O objetivo deste trabalho é buscar numa teoria da linguagem, primeiro, uma fundamentação e explicação para a atividade tradutora, e segundo, as ferramentas metodológicas para o seu ensino. Os postulados da Gramática Gerativotransformacional e suas implicações teóricas são propostos como válidos para a conceituação do processo tradutor. A partir daquele marco teórico foi esboçado um modelo explicativo. No campo da linguística aplicada um corpus de 50 erros de tradução (inglês-português) foi levantado, analisado e classificado, buscando-se esclarecer através da comparação as divergências e convergências bem como deter minar a causa dos erros. De tal análise foram deduzidas perspectivas metodológicas para o ensino da tradução com base na ciência linguística. 


\section{ÍNDICE}

\section{INTRODUÇÃO}

$1.1 \mathrm{O}$ problema

1.2 Objetivos

1.3 Método de trabalho

\section{DEFINIÇÃO DA TRADUÇÃO COMO OBJETO DE ESTUDO}

2.1 Definições teóricas

2.2 A tradução como parte de um contexto mais amplo

\section{TRADUÇÃO COMO ATIVIDADE LINGUÍSTICA}

3.1 Visão retrospectiva de teorias da linguagem

\subsubsection{Bloomfield}

3.1.2 Linguística distribucional

3.1.3 Sapir-Whorf

3.2. Três estudos sobre a tradução

3.2.1 Catford

3.2.2 Mounin

3.2.3 Nida

\section{A TRADUÇ̃̃O E A GRAMÁTICA GERATIVO-TRANSFORMACIONAL}

4.1 Teoria linguística explicativa

4.2 Análise componencial

4.3 Implicações dos conceitos de gramática gerativo-transformacional para uma teoria explicativa do processo tradutor

4.3.1 Capacidade inata e gramática universal

4.3.2 Competência e desempenho

4.3.3 Estrutura profunda e estrutura superficial

4.3.4 Transformações

4.3.5 Componentes

4.4 Aplicação dos conceitos de gramática gerativo-transformacional e um modelo explicativo da tradução

\section{TRADUÇÃO E LINGUÍSTICA APLICADA}

5.1 Análise contrastiva

5.2 Marco teórico e modelo para a análise contrastiva

5.2.1 Estrutura de base comum às várias línguas

5.2.2 Ordenação da estrutura de base

5.2.3 Direção da análise contrastiva

5.2.4 Identificação gramatical

5.2.5 Perda de relevância do item lexical

5.3 Método de análise

\section{ANÁLISE CONTRASTIVA DO CORPUS}

\subsection{Corpus}

6.2 Classificação - Explicação

6.2.1 Classe A

6.2.2 Classe B 
6.2.3 Classe C

6.2.4 Subclasses

6.3 Análise e Discussão

6.3.1 Classe A e subclasses

6.3.2 Classe B e subclasses

6.3.3 Classe $\mathrm{C}$ e subclasses

6.4 Considerações gerais

\section{CONCLUSÕES}

8. BIBLIOGRAFIA 


\section{INTRODUÇÃO}

\section{$1.1 \mathrm{O}$ problema}

Cada vez se torna mais evidente nos cursos de tradução de nível universitário a necessidade de se situar a atividade tradutora num marco de colocação teórica que, abrindo-lhe perspectivas mais amplas, ao mesmo tempo lhe forneça as ferramentas para uma análise mais precisa e rigorosa, levando a conclusões mais seguras. A disciplina exige um embasamento científico com poder explicativo de maior alcance que leve os seus realizadores a uma compreensão global tanto no seu aspecto linguístico como psicológico e sociológico. A par dessa necessidade de explicação teórica, sob o ponto de vista metodológico faz-se sentir a falta de uma orientação cientificamente fundamentada Não se pode continuar aceitando o ensino da tradução como mero exercício de uma habilidade conseguida à força de repetição, destreza e talento natural. Sem desprezar o valor daqueles três elementos no desenvolvimento da prática da tradução, o seu ensino, entretanto, requer o uso de técnicas fundamentadas em conceitos da ciência linguística, bem como de outras ciências afins.

Por outro lado, a bibliografia existente em nosso país e ao alcance da mão é escassa e, embora de autores de destaque no campo da linguística, não se revela particularmente útil para a tarefa visada. Em uma dessas obras (Mounin, 1963, p. 321) encontra-se observação idêntica. "Não há bibliografia geral referente à tradução como problema. Na sala de Catálogos da Biblioteca Nacional de Paris, no fichário por matérias (desde 1936) há umas 40 fichas de 'tradução'. A maioria dos títulos, exceto talvez uma dúzia, refere-se a repertórios de tradução".

Nida, em seu clássico sobre a tradução "Toward a Science of Translating" (1964), manifesta a mesma sensação de carência, citando Isenberg (1953, p. 234): “A verdade é que a arte da tradução superou amplamente a teoria da tradução", e justifica a existência da sua obra como "uma tentativa de remediar esse triste estado de coisas aportando ao tema da tradução inúmeras noções que têm cada vez mais se tornado significativas em inúmeras áreas afins”.

Diante desse quadro, impõe-se a tarefa ainda bastante desconhecida e inexplorada de buscar entre as ciências linguísticas um caminho para o ensino da tradução, quer para a sua conceituação teórica, quer como ferramenta metodológica. 


\subsection{Objetivo}

Delineia-se como objetivo do presente trabalho apontar as perspectivas para uma metodologia do ensino da tradução baseada numa teoria da linguagem. Esta, ao mesmo tempo que lhe serve de fundamentação e explicação teórica, deve fornecer-lhe através da linguística aplicada as ferramentas para uma análise mais rigorosa dos fatos e problemas referentes à tradução.

\subsection{Método de trabalho}

A fim de se atingir o objetivo fixado, alguns conceitos preliminares deverão ser levantados e precisados.

As seguintes etapas serão seguidas no desenvolvimento do trabalho:

1. A tradução será definida e situada no contexto mais amplo de outras atividades humanas e no contexto social total que representa.

2. Dentre os complexos aspectos sob os quais pode ser encarada a tradução, será destacado o aspecto nuclear e básico, o aspecto linguístico sobre o qual influem os outros e que constituirá o objeto deste estudo.

3. As contribuições de algumas teorias linguísticas à ciência da tradução serão revistas num enfoque crítico, ao mesmo tempo que algumas obras sobre o assunto serão analisadas, representantes que são daquelas mesmas correntes linguísticas. Tal visão prévia deverá indicar o que houve de positivo no passado e quais as contribuições esperadas de urna nova teoria que chegue a explicar convenientemente o processo da tradução.

4. Os postulados da Gramática Gerativo-Transformacional, considerada de grande valor explicativo no que se refere à tradução serão comentados, com suas implicações teóricas para a conceituação do processo tradutor. A partir daquele marco teórico esboçar-se-á um modelo explicativo da tradução.

5. No campo da linguística aplicada, buscar-se-ão técnicas contrastivas capazes de esclarecer as divergências e as convergências de duas línguas particulares, e de fornecer subsídios valiosos para a maior compreensão e aprofundamento da atividade tradutora.

6. Daí serão deduzidas as possibilidades metodológicas para o ensino da mesma. 


\section{CONCLUSÕES}

Conforme foi ressaltado nas paginas introdutórias deste trabalho, uma dupla preocupação se levantava ao redor do tema da tradução:

1 - encontrar uma conceituação teórica que explique cientificamente aquela atividade linguística altamente específica; e

2 - deduzir a partir daquela conceituação teórica uma metodologia que, dandolhe uma eficiência explicativa, integre o ensino da tradução ao campo da investigação e da ciência aplicada.

Nesse sentido, este estudo não pretendeu formular uma teoria da tradução, mas sim levantar alguns pontos para os quais deveria convergir uma reflexão produtiva sobre o assunto, pontos que seriam relevantes para definir a sua natureza, bem como precisar, dentro da totalidade do comportamento linguístico os seus objetivos e características.

A abordagem gerativo-transformacional, a nosso ver, ilumina devidamente os problemas teóricos não resolvidos pelas correntes linguísticas anteriores, abrindo perspectivas para estudos validos e produtivos, ao mesmo tempo que fornece uma ferramenta útil de análise na elaboração das técnicas e métodos para o ensino da tradução. Depois de esclarecidos os conceitos e identificados os problemas, partiu-se em busca da metodologia necessária.

Em vista dos conceitos ventilados no capítulo 4, principalmente em 4.3, onde se esboçou o que poderia vir a ser uma sugestão de modelo teórico da atividade tradutora, concluimos que uma metodologia do ensino da tradução deve se desenvolver a partir do conhecimento de dois pontos básicos:

1 - a transferência de significado não se faz no nível da superfície, onde cada língua é um universo linguístico fechado, mas sim na sua estrutura profunda, que é o conteúdo semântico de caráter universal.

2 - as estruturas fonológico-sintáticas com que temos contacto são as realizações superficiais, particulares a cada língua, daquele conteúdo semântico profundo.

Por outro lado, considerando:

- que a atividade tradutora resulta da atualização simultânea e da constante comparação de duas competências linguísticas, e

- que o tradutor deve possuir plenamente separadas e conscientemente distanciadas aquelas mesmas competências, 
uma metodologia eficaz para o ensino da traduçšo terá como objetivo amplo e geral ajudar o estudante a:

1 - desenvolver e reforçar a conscientização a respeito de sua competência tanto da língua nativa como da língua adquirida, e

2 - ser capaz de reconhecer e distinguir os recursos sintáticos e lexicais próprios de cada código, entre si ora divergentes, ora convergentes, nas realizações dos vários conteúdos semânticos.

Observando os exemplos examinados podemos inferir mais específica e concretamente que os erros encontrados se devem principalmente a:

1 - competência linguística imprecisa e não conscientizada;

2 - recursos sintático-lexicais ambiguamente misturados;

3 - fenômenos de interferência em ambas as direções;

4 - desconhecimento da distinção entre estrutura semântica profunda comum às diversas línguas e suas realizações superficiais específicas;

5 - desconhecimento da composição profunda dos itens lexicais em traços semânticos com características universais.

Com base nesse diagnóstico e tendo em mente as condições ideais de conhecimento de um tradutor, podemos deduzir mais precisamente que uma metodologia adequada deve levar o estudante a ser capaz de:

1 - distinguir clara e precisamente os recursos próprios dos códigos linguísticos com que trabalha;

2 - manter o devido distanciamento linguístico entre os mesmos códigos;

3 - reduzir ao mínimo os fenômenos de interferência;

4 - procurar o conteúdo semântico na estrutura profunda das sentenças a serem traduzidas, para a partir desse nível realizar a transferência de significado tanto no que diz respeito às estruturas sintáticas como às formas lexicais.

O esboço apresentado representa um conjunto de pontos a partir dos quais deveria desenvolver-se urna metodologia do ensino da tradução com fundamentação na linguística.

Com base nas premissas propostas, abrem-se múltiplas possibilidades de pesquisas de caráter contrastivo, que não só iluminariam detalhes desconhecidos dos códigos linguísticos particulares como também dariam novos subsídios para a metodologia visada para a tradução. 
Além daquelas perspectivas de análise tanto no nível sintático-semântico como lexical, conforme ficou exemplificado em nossa amostragem, seria do maior interesse que os resultados das pesquisas realizadas em Psicolinguística e Sociolinguística nos campos da aquisição da linguagem, da interferência linguística, da realidade psicológica das estruturas profunda e superficial etc., fossem proveitosamente utilizadas para a maior compreensão da atividade tradutora. $\mathrm{O}$ caminho a seguir é longo, as perspectivas são amplas, o desafio estimulante. Citando a frase bíblica, "a messe é grande e poucos os operários", com nossas conclusões juntamos nossas preocupações e interesse de que um maior número de estudiosos se interessem por esse campo relativamente negligenciado mas promissor. 